\title{
FORMACIÓN INICIAL DE EDUCADORAS PREESCOLARES: UNA EXPERIENCIA CENTRADA EN LA AUTODETERMINACIÓN DE LA INFANCIA PREESCOLAR ${ }^{1}$
}

Preschool teacher initial training: an experience focused on the preschooler selfdetermination

Treinamento inicial de educadores de jardim de infância: uma experiência centrada na autodeterminação da infância pré-escolar

\section{Rolando Angel-Alvarado}

Universidad Pública de Navarra (España). Telf.: (034) 632192 469. Correo electrónico: rolando.angel.alvarado@gmail.com ORCID: http://orcid.org/0000-0002-1800-2667

\section{María José Cisternas Hormazábal}

Universidad de Chile. Telf.: (056) 973642 811. Correo electrónico:

mariajosecisternash@hotmail.com

\section{Javiera Molina Barros}

Universidad de Chile. Telf.: (056) 974005 688. Correo electrónico: janamoba@gmail.com

\section{Valeria San Martín Carmona}

Universidad de Chile. Telf.: (056) 978104 992. Correo electrónico: vale.8jo@gmail.com

\section{Resumen}

En la infancia preescolar, la música es fundamental porque estimula el pensamiento creativo mediante la audición, la interpretación y la composición. Así, la carrera de Educación Parvularia y Básica Inicial de una universidad pública chilena ha implementado un curso optativo centrado en la estimulación musical para que el cuerpo estudiantil aprenda a construir y validar experimentalmente situaciones didácticas. El objetivo de este estudio es escribir una teoría para promover el comportamiento autodeterminado de la infancia preescolar, según las situaciones didácticas validadas por las estudiantes

${ }^{1}$ Se agradece a la Carrera de Educación Parvularia y Básica Inicial de la Universidad de Chile por la gestión de la asignatura. 
universitarias. El método responde a la pedagogía hermenéutica porque la teoría y la praxis interactúan constantemente. Los resultados demuestran que el comportamiento autodeterminado y el pensamiento de orden superior se retroalimentan mutuamente. En conclusión, existe una espiral continua entre el pensamiento de orden superior y la autodeterminación.

Palabras clave: educación musical; formación de docentes de preescolar; niño en edad preescolar; autodeterminación.

\begin{abstract}
In preschoolers, music is essential because it encourages the creative thinking through listening, interpretation, and composition. Within this framework, the Preschool \& Primary Education career belonging to a Chilean public university, it has offered an optative course focused on musical stimulation in order to college students learn to build and experimentally validate didactical situations. This research aims to write a theory for promoting the self-determined behaviour in preschoolers, according to the didactical situations validated by college students. The method responds to hermeneutic pedagogy because theory and praxis are interacting constantly. The results show that self-determined behaviour and the higher order thinking share benefits reciprocally. In conclusion, there is a continuous spiral between the higher order thinking and self-determination.
\end{abstract}

Key words: music education; preschool teacher education; preschoolers; selfdetermination.

\title{
Resumo
}

Em pré-escolares, a música é essencial porque encoraja o pensamento criativo através da escuta, interpretação e composição. Em conformidade com este quadro, a carreira de educação pré-escolar e primária pertencente a uma universidade pública chilena ofereceu um curso optativo focado em estimulação musical para que estudantes universitários aprendam a construir e validar experimentalmente situações didáticas. Esta pesquisa visa escrever uma teoria para promover o comportamento autodeterminado em pré-escolares, de acordo com as situações didáticas validadas por estudantes universitários. O método responde à pedagogia hermenêutica porque a teoria e o práxis estão interagindo 
constantemente. Os resultados mostram que o comportamento autodeterminado eo pensamento de ordem superior são feedback mutuamente. Em conclusão, há uma espiral contínua entre o pensamento da ordem superior e a autodeterminação.

Palavras-chave: educação musical; educação pré-escolar em professores; pré-escolares; autodeterminação.

\section{Introducción}

En la infancia preescolar (cuatro a seis años) se experimenta la creatividad desde la actitud perceptiva y la fantasía, de modo que las situaciones didácticas deben estar cargadas de experiencias sensoriales que promuevan la imaginación constructiva (Van Leeuwen, 2016). En este marco, la música se instala como una disciplina que favorece el aprendizaje y desarrollo del pensamiento creativo porque, desde la curiosidad artística, potencia la imaginación al promover actividades perceptivas y expresivas mediante las acciones musicales de escucha, interpretación y composición. Por ello, es fundamental que el profesorado de educación parvularia adquiera las competencias musicales que favorezcan la potenciación del pensamiento creativo (Ivanova, 2014).

Por un lado, las actividades de audición sonoro-musical promueven la construcción de imágenes perceptivas personales (Delalande, 2001) que inciden en las otras acciones musicales. Por otro lado, las actividades de interpretación y creación musical comprenden un ascenso que comienza en la exploración sonora y el descubrimiento, pasando por la imitación, la recreación y la improvisación, alcanzando finalmente la composición mediante la construcción sonoro-musical (Delalande, 2013). Todas estas actividades dan cuenta que la música, por su naturaleza, favorece la adquisición y desarrollo del pensamiento creativo.

Considerando estos antecedentes, se implementa en la carrera de Educación Parvularia y Básica Inicial de una universidad pública chilena, una asignatura complementaria que aborda los aspectos específicos de la estimulación musical para la primera infancia, considerando las etapas del desarrollo creativo y los modos evolutivos de la musicalidad desde un enfoque constructivista (Arguedas, 2004). Por lo tanto, la asignatura establece espacios de formación práctica que fomentan la elaboración de situaciones didáctico-musicales y su realización concreta en escuelas de párvulos durante 
las prácticas pedagógicas iniciales o profesionales. Así, la carrera universitaria acepta la directa incidencia que tiene la práctica instruccional del profesorado en el éxito de la educación parvularia (Koutsoftas, Dubasik y Moss, 2017).

Las situaciones didáctico-musicales que surgen en el marco de la asignatura complementaria deben impulsar, al interactuar entre sí, la escritura de una teoría referida a la potenciación del comportamiento autodeterminado de la infancia preescolar, lo que implica favorecer el bienestar personal y la integración social de los individuos en el marco de un desarrollo ético y estético de la persona humana (Nielsen, 2007).

Con todo esto, el presente estudio establece el siguiente objetivo: Escribir una teoría para promover el comportamiento autodeterminado de la infancia preescolar, en base a las situaciones didáctico-musicales que han diseñado y validado experimentalmente estudiantes de la carrera de Educación Parvularia y Básica Inicial de una universidad pública chilena. Para alcanzar este objetivo, se analizan tres situaciones didáctico-musicales que se han aplicado experimentalmente en contextos de educación preescolar, específicamente en los niveles de transición según la estructura curricular chilena (Ministerio de Educación, 2005). Por consiguiente, este estudio está dirigido a académicos que imparten la asignatura de música en contextos de formación inicial, tanto del profesorado de educación parvularia como de las asistentes de la educación; como también a profesionales de la educación que desempeñan funciones pedagógico-musicales en niveles de educación preescolar.

\section{Metodología}

Se emplea la pedagogía hermenéutica ya que la interacción recíproca entre la investigación didáctica y la actividad de aula es planteada como una espiral hermenéutica según la Didáctica Filosófica de la Música (Georgii-Hemming y Lilliedahl, 2014). Así, la teoría didáctica influye en las determinaciones pedagógicas que definen las experiencias de enseñanza/aprendizaje, mientras que la actividad efectiva de aula aporta conocimientos nuevos al sistema de ideas que el profesorado construye sobre la didáctica.

Este ciclo hermenéutico de la didáctica de la música se comprende como bildung (Nielsen, 2007) porque la formación musical promueve desde la razón, la construcción autodeterminada del ser humano, tomando en cuenta el bienestar personal y la integración 
social en el desarrollo ético y estético de la persona humana. Así, diversas corrientes teóricas sobre la bildung musical se han postulado, donde en términos generales, las teorías formativas se focalizan en la relación entre el sujeto y el objeto, mientras que las corrientes empíricas se concentran en la dualidad persona-sociedad (Jank, 2014).

La presente investigación enmarca la bildung musical en la didáctica antropológica de la música (Georgii-Hemming y Lilliedahl, 2014) porque focaliza las experiencias académicas en la autodeterminación infantil, poniendo su atención en las situaciones didáctico-musicales diseñadas y validadas por las estudiantes universitarias, con el afán de escribir una teoría que promueva el comportamiento autodeterminado de la infancia preescolar.

\subsection{Contexto y participantes}

En la carrera de Educación Parvularia y Básica Inicial impartida en una universidad pública chilena, se ha dictado la asignatura complementaria Estimulación Musical en la Primera Infancia. El objetivo del curso es abordar los aspectos específicos de la estimulación musical, considerando las etapas del desarrollo creativo y los modos evolutivos de la musicalidad.

Para cumplir este objetivo, el programa curricular ha planteado el desarrollo auditivo, creativo y musical del ser humano, desde la etapa lactante hasta la edad preescolar, proporcionando la adquisición y desarrollo de: 1) Metodologías y modelos pedagógicos para la potenciación sociomusical de la primera infancia; 2) Competencias para confeccionar experiencias musicales vinculadas a la estimulación sensorial, afectiva y creativa de la primera infancia y; 3) Criterios para la selección de repertorios y materiales según las capacidades infantiles, tanto psíquicas como motoras.

La asignatura no solo plantea clases expositivas para abordar el desarrollo creativo y musical de la primera infancia, sino que principalmente establece espacios de participación activa mediante talleres que impliquen la elaboración y ejecución de proyectos didácticomusicales, para atender problemáticas en contextos escolares concretos durante las prácticas pedagógicas. 
Como actividad formativa obligatoria, se deben confeccionar situaciones didácticomusicales para todos los niveles educativos que establece el sistema curricular chileno para la primera infancia (Ministerio de Educación, 2005): sala cuna (edades desde 84 días a 2 años), niveles medios (edades desde 2 a 4 años) y niveles de transición (edades desde 4 a 6 años). No obstante, cada estudiante tiene la obligación de ejecutar solo una construcción didáctica en el nivel educativo donde ejerce su práctica pedagógica inicial o profesional. Al final del curso, las estudiantes deben presentar la planificación curricular correspondiente, los recursos didácticos, la evidencia gráfica o audiovisual del desarrollo de la actividad y un ensayo que proporcione la fundamentación teórica de la actividad ya validada experimentalmente.

Finalmente, se observa que tres estudiantes han efectuado su práctica pedagógica en los niveles de transición, cuales atienden a la infancia preescolar; situándose todas las escuelas de párvulos en la Región Metropolitana. En consecuencia, estas tres situaciones didácticas se recogen como material para llevar a cabo la escritura teórica.

\subsection{Materiales}

Las situaciones didáctico-musicales apuntan hacia actividades musicológicas distintas, de modo que se exponen los elementos generales de cada una. Estas tres situaciones didácticas son relevantes para el profesorado porque promueven la conquista del aula musical en contextos de educación parvularia, desde una perspectiva centrada en la transformación cultural de las educadoras preescolares.

- Situación didáctico-musical $N^{\circ} 1$ : Se estima que el repertorio musical infantil promueve un enfoque adulto-centrista que limita la potenciación de la creatividad en la infancia preescolar. En respuesta, se propone construir didácticas musicales focalizadas en el descubrimiento de la composición lírica (Delalande, 2013), tras abogar que la canción infantil es determinante para el desarrollo de la memoria y el aprendizaje significativo (Bergman, Darki y Klingberg, 2014) porque abarca las emociones de los preescolares (Peplak, Song, Colasante y Malti, 2017). En este cometido, se diseña una actividad centrada en la creación lírica colectiva, utilizando pictogramas digitales para el registro composicional. En la experiencia empírica, se observa que los preescolares logran recordar la actividad en el tiempo, como también, relacionarla con otras experiencias 
similares. Por lo tanto, la situación didáctica promueve la adquisición y desarrollo de aprendizajes significativos porque los párvulos asumen un rol activo dentro del contrato didáctico. En conclusión, el enfoque infanto-céntrico toma en cuenta el descubrimiento para la potenciación creativa de los preescolares.

- Situación didáctico-musical No2: Se centra en la imaginación de la infancia preescolar, entendiéndola como una actitud perceptiva que permite ir más allá de lo aprendido (De la Torre, 1997) para expresarse concretamente. Establece que la imaginación demanda conocimientos previos que solamente pueden adquirirse tras desarrollar la función simbólica de la consciencia (Uralde-Cancio, 2011) porque exige reconocer que los elementos (animados o inanimados) se componen por partes y ejercen roles o funciones (por ejemplo, una mano o una botella). Así, se construye una actividad centrada en la fantasía, ya que, por medio de la voz y el cuerpo, los preescolares deben expresar las representaciones mentales que un paisaje sonoro les evoca (Lavanchy, 2013). La evidencia experimental demuestra que los párvulos son capaces de expresar sus representaciones mentales a través de la voz y el cuerpo, adquiriendo nuevos conocimientos sobre sí mismos porque asumen un rol activo en la actividad. En conclusión, la situación didáctico-musical potencia el desarrollo de la imaginación y el autoconocimiento.

- Situación didáctico-musical N³: Se centra en la estimulación sensorial de la infancia preescolar para la potenciación del pensamiento de orden superior (Lipman, 1998): creativo, crítico y afectivo. Para ello, considera los modos evolutivos de la musicalidad (Arguedas, 2004) y el pragmatismo musical (Elliott, 1995), haciendo notar que el aprendizaje transita desde lo abstracto a lo concreto solo cuando el contexto proporciona experiencias estéticas (Gutiérrez y Castillo, 2014). Así, se construye una actividad que plantea discutir los elementos sonoro-musicales y situacionales que posee una audición dirigida, estableciendo instancias para definir los elementos sonoromusicales, intercambiar opiniones críticas sobre la audición y manifestar las emociones que evoca la experiencia. La evidencia empírica demuestra que los preescolares identifican sonidos que no visualizan, como también expresan ideas críticas y afectivas sobre la experiencia. En conclusión, la actividad potencia el pensamiento de orden 
superior porque los estímulos sensoriales incitan el pensamiento abstracto mediante lo crítico, creativo y afectivo, concretándose por medio de discursos espontáneos que exhiben el mundo interior del sujeto.

\subsection{Procedimiento}

En conformidad a las tres situaciones didáctico-musicales validadas por las estudiantes universitarias, se construye una red objetiva dónde interactúa la bildung musical con los aspectos sensoriales, afectivos y creativos de la infancia preescolar. La evolución teórica se expresa a través de una red objetiva, dando lugar a la escritura teórica que sustenta la potenciación del comportamiento autodeterminado de la infancia preescolar.

La escritura teórica se lleva a cabo mediante el Método Comparativo Constante (MCC) basado en el razonamiento inductivo (Carrero, Soriano y Trinidad, 2012), ya que los resultados generales del estudio surgen de los datos particulares que aportan las estudiantes universitarias, tras compartir sus experiencias pedagógicas en el marco de la actividad formativa obligatoria que establece la asignatura. Dentro de este marco, las premisas praxeológicas que surjan del análisis se contrastan con la literatura científica, con el afán de establecer la escritura teórica (San Martín, 2014).

\section{Resultados y su discusión}

Las tres situaciones didáctico-musicales presentadas por las estudiantes sirven como material para construir la red objetiva, donde interactúa la bildung musical con los aspectos sensoriales, afectivos y creativos de la infancia preescolar. No obstante, es fundamental asumir que dichas situaciones didáctico-musicales y, por ende, la red objetiva, están construidas y validadas para su ejercicio en contextos de infancia preescolar (edades de cuatro a seis años) porque demandan competencias psíquicas y cognitivas ya superadas por los preescolares. Por ejemplo:

- La función simbólica de la consciencia (Uralde-Cancio, 2011) permite al preescolar percibir las partes y funciones de un objeto; mientras que un lactante o un menor en edad temprana (edades de 1 a 3 años) solo percibe un objeto como un todo.

- El pensamiento por esquemas, que implica recordar la actividad en el tiempo y relacionarla con otras experiencias similares (Rodríguez, 2012). 
- Integración entre el pensamiento por esquemas y el pensamiento lógico (Rodríguez, 2012), se entiende como el acto de construir relaciones entre elementos (situaciones, seres animados e inanimados) y su asimilación mediante palabras y signos.

- El pensamiento por representación (Vilar, 2004), que implica representar mentalmente situaciones, seres animados e inanimados, prescindiendo de su presencia física.

\subsection{Red objetiva}

Las tres situaciones didáctico-musicales convergen en que la infancia preescolar debe asumir un rol activo y protagonista durante la actividad para fomentar la adquisición y desarrollo de aprendizajes significativos que favorezcan el comportamiento autodeterminado fundado en el bienestar personal y la integración social.

Las situaciones didáctico-musicales se plantean desde una perspectiva multidimensional (Figura 1), dónde influye el pensamiento de orden superior (Lipman, 1998): crítico, creativo y afectivo. De este modo, el pensamiento crítico es inseparable del pensamiento creativo y el pensamiento afectivo (Lipman, 2004) porque lo crítico se representa como una idea propia, original y novedosa, que está cargada del afecto que el sujeto le atribuye en base a la información sensorial, perceptiva y reflexiva de su dominio.

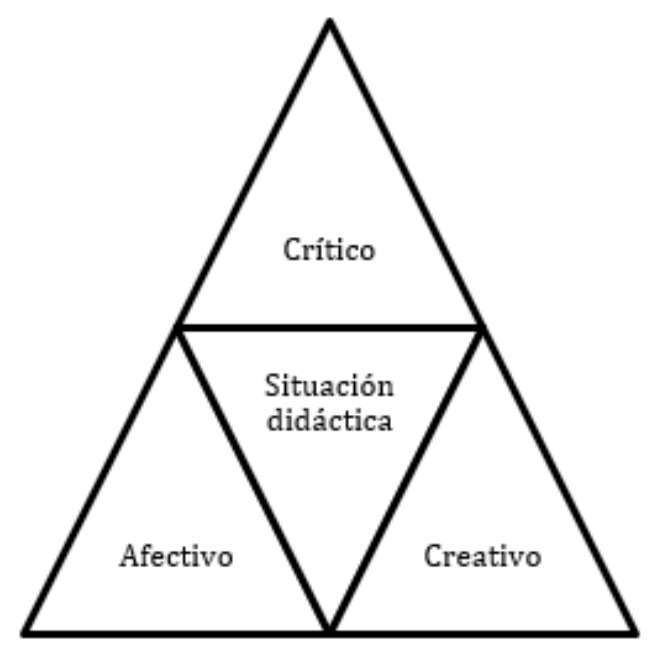

Figura 1. Perspectiva multidimensional de la situación didáctica

Las tres situaciones didáctico-musicales que se han reportado, dan cuenta de la potenciación del pensamiento de orden superior mediante la construcción de canciones, 
expresiones corporales y discursos. Dichas acciones impulsan el pensamiento creativo al hacer tangibles u observables las ideas propias de los preescolares; promueven el pensamiento afectivo por medio de la memoria y la evocación de emociones y; potencian el pensamiento crítico al promover la expresión de opiniones. En consecuencia, la potenciación del pensamiento de orden superior favorece la autodeterminación preescolar porque los párvulos viven experiencias éticas y estéticas que les permiten descubrir su mundo interior y la cultura.

Por consiguiente, el pensamiento de orden superior se potencia mediante el pensamiento por esquemas, al interaccionar los conocimientos previos con las experiencias éticas y estéticas que se viven durante la situación didáctico-musical. Estas interacciones permiten la construcción de nuevas relaciones entre los elementos sociomusicales y su asimilación semiótica (Rodríguez, 2012). En consecuencia, los preescolares adquieren y desarrollan nuevos conocimientos en el marco del comportamiento autodeterminado para el bienestar personal y la integración social porque asumen un rol activo en el contrato didáctico, que les permite tomar consciencia de sus propios conocimientos previos (Bergman et al., 2014) y descubrir tanto su mundo interior como el capital cultural (Delalande, 2013).

No obstante, para propiciar la adquisición de estos nuevos conocimientos enmarcados en la autodeterminación, es esencial que las situaciones didáctico-musicales sean percibidas y representadas por los preescolares como instancias lúdicas, de modo que las actividades deben mostrar una profunda vinculación con la estimulación sensorial, el juego de rol y la resolución de problemas. Para alcanzar este cometido, las tres situaciones didáctico-musicales reportadas se han orientado hacia la potenciación de las competencias sensoriales, sensoriomotoras y perceptivo-cognitivas (Angel-Alvarado, 2017), lo que ha sido determinante para la gestión de grupos preescolares participativos durante las situaciones didáctico-musicales.

En definitiva, la evolución teórica expresada por esta red objetiva establece que las actividades sonoro-musicales que estimulan los aspectos sensoriales, afectivos y creativos, favorecen la autodeterminación de la infancia preescolar. En otras palabras, la red objetiva demuestra que las actividades sonoro-musicales que incorporan los aspectos sensoriales, en 
conjunto con el pensamiento de orden superior (crítico, afectivo y creativo), potencian el comportamiento autodeterminado porque los preescolares actúan en función del placer que la tarea les provoca, mostrando sentido de voluntad y capacidad de elección. Por lo tanto, esta descripción muestra cierta concordancia con la Teoría de la Autodeterminación (Evans, 2015) ya que la potenciación del comportamiento autodeterminado favorece el desempeño en actividades creativas y en tareas que demandan soluciones efectivas (Gagné, 2009).

El discurso de la Teoría de la Autodeterminación apunta en un sentido opuesto a la teoría expresada por la red objetiva, sin embargo, en términos holísticos, ambos discursos muestran la existencia de una espiral sistemática y continua (Figura 2), ya que, según la red objetiva, el pensamiento de orden superior favorece el comportamiento autodeterminado; mientras que la Teoría de la Autodeterminación establece que la potenciación del comportamiento autodeterminado favorece el pensamiento de orden superior. Tomando en cuenta el esquema de interacciones didácticas donde participa el estudiante, el profesorado, la musicología y el contexto (Sicherl, Kordeš y Holcar, 2017), se observa que el estudiante preescolar está representado por el comportamiento autodeterminado y el contenido musicológico se vincula al pensamiento de orden superior. En este marco, el profesorado y el contexto asumen un rol mediador que debe garantizar las condiciones ambientales para la retroalimentación sistemática entre ambas corrientes teóricas.

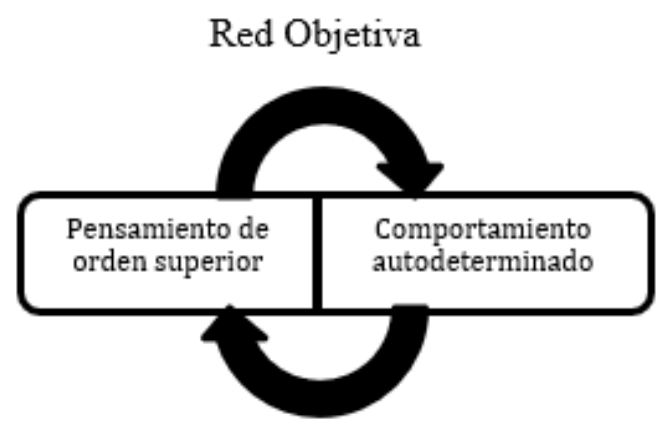

Teoría de la Autodeterminación

Figura 2. Espiral sistemática entre la Red Objetiva y la Teoría de la Autodeterminación.

\section{Conclusiones}

Todo currículo establece un marco normativo para las situaciones didácticas, pero no necesariamente esta norma asegura la implementación de estrategias que fomenten el 
comportamiento autodeterminado de los estudiantes. Por lo tanto, es imperioso alcanzar modelos pedagógicos focalizados en la formación autodeterminada, ya que centran el proceso educativo en el aprendizaje del estudiante, dejando atrás el tradicional modelo centrado en los contenidos de enseñanza.

Este paradigma de la educación musical reconoce que la interacción didáctica se adecúa al estudiante, al saber musicológico, al docente y al contexto. Así, el estudiante es el centro de la situación didáctica, el saber musicológico se asume como el elemento primario que propicia la interacción, mientras que el profesorado y el contexto toman roles mediadores o de colaboración entre el conocimiento musicológico y el/la estudiante.

En este marco, las situaciones didáctico-musicales reportadas potencian el pensamiento creativo porque son capaces de promover, a la vez, el pensamiento crítico y el pensamiento afectivo, siendo todos parte del pensamiento de orden superior. En concreto, el pensamiento crítico se representa como una idea propia, original y novedosa, que está cargada del afecto que el individuo le atribuye, basándose en la información sensorial, perceptiva y reflexiva de su dominio. Por lo tanto, las tres formas de pensamiento se retroalimentan unas a otras, dando lugar al pensamiento de orden superior.

Para pensar creativa, crítica y afectivamente, es necesario promover el comportamiento autodeterminado fundado en el bienestar personal y la integración social, porque todo individuo autodeterminado es capaz de efectuar sus tareas mostrando gozo, voluntad y capacidad de elección. De modo que los contextos que impulsan el comportamiento autodeterminado, logran que sus comunidades muestren mejor desempeño en actividades creativas y en tareas que demandan resoluciones efectivas.

En conclusión, la evolución teórica de la red objetiva da cuenta que las actividades sonoro-musicales que estimulan los aspectos sensoriales, afectivos y creativos, si favorecen la autodeterminación en la infancia preescolar. Por lo tanto, la teoría propuesta define que existe una espiral sistemática y continua entre el pensamiento de orden superior y el comportamiento autodeterminado del preescolar ya que ambas corrientes teóricas se retroalimentan con reciprocidad de manera permanente.

Con todo esto, se cumple el objetivo de investigación porque se ha escrito una teoría para la promoción del comportamiento autodeterminado en la infancia preescolar, en base a 
las situaciones didáctico-musicales que han diseñado y validado experimentalmente estudiantes de la carrera de Educación Parvularia y Básica Inicial de una universidad pública chilena.

Más allá que la teoría expuesta se circunscriba a la realidad de una universidad concreta, se estima que el enfoque didáctico-musical propuesto puede aplicarse en otras realidades universitarias de la región porque, en términos generales, plantea abordar la didáctica musical para la educación infantil desde una perspectiva decolonial, buscando impulsar la construcción del comportamiento autodeterminado en el estudiante preescolar.

\section{Referencias bibliográficas}

Angel-Alvarado, R. (2017). El desarrollo auditivo en la primera infancia: Compendio de evidencias científicas relevantes para el profesorado. Revista Electrónica Educare, 21, 1, 1-8. doi: 10.15359/ree.21-1.4

Arguedas, C. (2004). La expresión musical y el currículo escolar. Revista Educación, 28, 1, 111-122.

Bergman, S., Darki, F. y Klingberg, T. (2014). Music practice is associated with development of working memory during childhood and adolescence. Frontiers in Human Neuroscience, 7, 1-9. doi: 10.3389/fnhum.2013.00926

Carrero, V., Soriano, R. y Trinidad, A. (2012). Teoría fundamentada Grounded theory: El desarrollo de la teoría desde la generalización conceptual. Madrid: Centro de Investigaciones Sociológicas.

Delalande, F. (2001). La música es un juego de niños. Buenos Aires: Ricordi Americana.

Delalande, F. (2013). Las conductas musicales. Santander: Universidad de Cantabria.

De la Torre, S. (1997). Creatividad y Formación: Identificación, diseño y evaluación. Archidona: Aljibe.

Elliott, D. J. (1995). Music Matters: A new philosophy of music education. Nueva York: SAGE.

Evans, P. (2015). Self-determination theory: An approach to motivation in music education. Musicae Scientiae, 19, 1, 65-83. doi: 10.1177/1029864914568044 
Gagné, M. (2009). A model of knowledge-sharing motivation. Human Resource Management, 48, 4, 571-589. doi: 10.1002/hrm.20298

Georgii-Hemming, E. y Lilliedahl, J. (2014). Why "what" on the content dimensions of music didactics. Philosophy of Music Education Review, 22, 2, 132-155.

Gutiérrez, E. y Castillo, J. A. (2014). Reflexiones sobre la concepción del cuerpo y del movimiento para una educación integral de la primera infancia. Praxis Pedagógica, $14,15,15-42$.

Ivanova, A. (2014). La competencia musical del docente de Educación Infantil. Madrid: CCS.

Jank, W. (2014). Didaktik, bildung, content on the writings of Frede V. Nielsen. Philosophy of Music Education Review, 22, 2, 113-131.

Koutsoftas, A. D., Dubasik, V. L. y Moss, A. (2017). Preschool teachers' endorsement of instructional practices: An interprofesional exploration. Educational Research, 59, 1, 36-53. doi: 10.1080/00131881.2016.1267581

Lavanchy, C. (2013). Musicando con las bases curriculares. Educarte, 46-47, 20-26.

Lipman, M. (1998). Pensamiento complejo y educación. Madrid: De la Torre.

Lipman, M. (2004). Natasha: aprender a pensar con Vygotsky: una teoría narrada en clave de ficción. Barcelona: Gedisa.

Ministerio de Educación. (2005). Bases curriculares de la educación parvularia. Santiago: Unidad de Currículum y Evaluación.

Nielsen, F. (2007). Music (and Arts) Education from the point of view of didaktik and bildung. En L. Bresler (Eds.) International handbook of research in arts education (pp. 265-285). Nueva York: Springer.

Peplak, J., Song, J. H., Colasante, T. y Malti, T. (2017). “Only you can play with me!” Children's inclusive decision making, reasoning, and emotions based on peers' gender and behavior problems. Journal of Experimental Child Psychology, 162, 134-148. doi: 10.1016/j.jecp.2017.04.019 
Rodríguez, A. (2012). Lecturas de psicología preescolar. La Habana: Pueblo y Educación.

San Martín, D. (2014). Teoría fundamentada y Atlas.ti: Recursos metodológicos para la investigación educativa. Revista Electrónica de Investigación Educativa, 16, 1, 104122.

Sicherl, B., Kordeš, U. y Holcar, A. (2017). Assessment for learning in music education in the Slovenian context - from punishment or reward to support. Music Education Research, 19, 1, 17-28. doi: 10.1080/14613808.2015.1077800

Uralde-Cancio, M. (2011). La creatividad en la educación plástica desde la primera infancia. Varona, 53, 40-45.

Van Leeuwen N. (2016). Imagination and action. En A. Kind (Ed.), The Routledge Handbook of Philosophy of Imagination (pp. 286-299). Oxon: Routledge.

Vilar, M. (2004). Acerca de la educación musical. Revista LEEME, 13, 1-23. 